\title{
METODE PENGENDAPAN DAN PENUKAR KATION UNTUK PEMISAHAN CESIUM DALAM BAHAN BAKAR $\mathrm{U}_{3} \mathrm{Si}_{2}$-Al
}

\author{
Aslina Br. Ginting, Dian Anggraini \\ Pusat Teknologi Bahan Bakar Nuklir-BATAN \\ Kawasan Puspiptek, Serpong, Tangerang Selatan, 15314 \\ e-mail: aslina@batan.go.id
}

(Naskah diterima : 23-04-2016, Naskah direvisi: 16-05-2016, Naskah disetujui: 24-05-2016)

\begin{abstract}
ABSTRAK
METODE PENGENDAPAN DAN PENUKAR KATION PADA PROSES PEMISAHAN CESIUM

DALAM BAHAN BAKAR $\mathrm{U}_{3} \mathrm{Si}_{2}$-Al. Isotop ${ }^{137} \mathrm{Cs}$ salah satu hasil fisi yang dapat digunakan sebagai monitor burn up untuk mempelajari kinerja bahan bakar selama iradiasi dalam reaktor. Untuk menganalisis isotop ${ }^{137} \mathrm{Cs}$ dalam pelat elemen bakar (PEB) $\mathrm{U}_{3} \mathrm{Si}_{2}-\mathrm{Al}$ pasca iradiasi diperlukan metode yang valid agar diperoleh data yang akurat. Beberapa metode dapat digunakan untuk pemisahan ${ }^{137} \mathrm{Cs}$ dalam $\mathrm{PEB} \mathrm{U}_{3} \mathrm{Si}_{2}$ - $\mathrm{Al}$, antara lain adalah metode pengendapan dalam bentuk garam $\mathrm{CsClO}_{4}$ sesuai dengan ASTM E 320-79 dan metode penukar kation menggunakan zeolit Lampung. Proses pengendapan dilakukan dengan menggunakan serbuk $\mathrm{CsNO}_{3}$ sebagai senyawa pembawa (carier) dan pereaksi $\mathrm{HClO}_{4}$, sedangkan proses penukar kation dilakukan dengan penambahan zeolit Lampung. Tujuan penelitian adalah mendapatkan metode valid untuk pemisahan ${ }^{137} \mathrm{Cs}$ dalam $\mathrm{PEB} \mathrm{U}_{3} \mathrm{Si}_{2}$ - $\mathrm{Al}$ pasca iradiasi, khususnya aspek pengaruh berat serbuk $\mathrm{CsNO}_{3}$ dan berat zeolit Lampung yang ditambahkan. Proses pengendapan isotop ${ }^{137} \mathrm{Cs}$ dilakukan dengan memipet larutan $\mathrm{PEB} \mathrm{U}_{3} \mathrm{Si}_{2}$-Al sebanyak $150 \mu \mathrm{L}$ kemudian ditambahkan serbuk $\mathrm{CsNO}_{3}$ dengan variasi berat 500; 625; 700 ; dan $1000 \mathrm{mg}$ serta $4 \mathrm{~mL} \mathrm{HClO}_{4}$ dalam pengangas es selama 1 jam. Hasil proses pengendapan diperoleh endapan ${ }^{137} \mathrm{CsClO}_{4}$ yang terpisah dengan supernatan sebagai fasa cair.Sementara itu, proses penukar kation dilakukan dengan menambahkan zeolit Lampung variasi berat 700; 900; 1000 ; dan $1200 \mathrm{mg}$ dengan pengadukan selama 1 jam. Hasil proses penukar kation diperoleh padatan ${ }^{137} \mathrm{Cs}$-zeolit dalam fasa padat dan isotop lainnya dalam fasa cair. Endapan ${ }^{137} \mathrm{CsClO}_{4}$ dan padatan ${ }^{137} \mathrm{Cs}$-zeolit serta supernatan diukur kandungan ${ }^{137} \mathrm{Cs}$ menggunakan spektrometer- $\gamma$. Hasil analisis menunjukkan bahwa berat $\mathrm{CsNO}_{3}$ yang paling banyak mengikat ${ }^{137} \mathrm{Cs}$ terjadi pada penambahan $\mathrm{CsNO}_{3}$ seberat $700 \mathrm{mg}$ yaitu sebesar $0,0472 \mu \mathrm{g}$, sedangkan penambahan zeolit Lampung yang optimal diperoleh pada berat $1000 \mathrm{mg}$ hingga $1200 \mathrm{mg}$ dengan kandungan isotop ${ }^{137} \mathrm{Cs}$ dalam padatan ${ }^{137} \mathrm{Cs}$-zeolit diperoleh sebesar $0,0557 \mu \mathrm{g}$. Pemisahan isotop ${ }^{137} \mathrm{Cs}$ menggunakan metode penukar kation dengan penambahan zeolit Lampung $1000 \mathrm{mg}$ hingga $1200 \mathrm{mg}$ mempunyai hasil lebih baik bila dibandingkan dengan metode pengendapan. Selain itu, pengerjaan dengan metode penukar kation lebih mudah serta lebih aman bila dibandingkan dengan metode pengendapan yang pengerjaannya harus dalam penggangas es $(-4 \stackrel{\circ}{\circ})$, menggunakan bahan kimia $\mathrm{HClO}_{4}$ dengan aceton dan etanol yang bersifat volatil dan eksotermik.
\end{abstract}

Kata kunci: isotop ${ }^{137} \mathrm{Cs}$, zeolit, serbuk $\mathrm{CsNO}_{3}$, metode penukar kation dan pengendapan 


\section{ABSTRACT}

\section{PRECIPITATION METHOD AND KATION EXCHANGE METHOD FOR CESIUM SEPARATION}

OF $U_{3} \mathrm{Si}_{2}$-AI FUEL ELEMENT. ${ }^{137} \mathrm{Cs}$ isotope was one of the fission products which could be used as a burn up monitor to study the performance of the fuel during irradiation in a reactor. For analyzed ${ }^{137} \mathrm{Cs}$ isotope in post-irradiation $\mathrm{U}_{3} \mathrm{Si}_{2}$-Al fuel element plate (PEB), it was needed a valid method to obtain accurate data. Several methods could be used for ${ }^{137} \mathrm{Cs}$ separation from $\mathrm{U}_{3} \mathrm{Si}_{2-}$ Al PEB solution were precipitation method in $\mathrm{CsClO}_{4}$ salt form according to ASTM E 320-79 and cation exchange method using Lampung zeolite. The precipitation process was done using $\mathrm{CsNO}_{3}$ powder as a carrier substance and $\mathrm{HClO}_{4}$ reagent, while the cation exchange process was done by the addition of Lampung zeolite. The objective research was getting a valid method for ${ }^{137} \mathrm{Cs}$ separation in post-irradiation $\mathrm{U}_{3} \mathrm{Si}_{2}-\mathrm{Al} \mathrm{PEB}$, especially for the aspects of $\mathrm{CsNO}_{3}$ powder weight influence and weight of zeolite Lampung was added. ${ }^{137} \mathrm{Cs}$ isotope precipitation process was done by pipetting $150 \mathrm{~mL} \mathrm{U}_{3} \mathrm{Si}_{2}-A$ I PEB solution which was added to the 500; 625; 700; and $1000 \mathrm{mg}$ weight variation $\mathrm{CsNO}_{3}$ powder and $4 \mathrm{~mL} \mathrm{HClO}$ in ice media for 1 hour. The precipitation process results was obtained $\mathrm{CsClO}_{4}$ precipitate separated from the supernatant as a liquid phase. Mean while, the cation exchange process was done by adding 700; 900; 1000 and $1200 \mathrm{mg}$ weight variation Lampung zeolite by shaking for 1 hour. The cation exchange process results was obtained ${ }^{137} \mathrm{Cs}$-zeolite in the solid phase and the other isotopes in the liquid phase. The ${ }^{137} \mathrm{Cs}$ content in ${ }^{137} \mathrm{CsClO}$ precipitate, ${ }^{137} \mathrm{Cs}$-zeolite solid phase and supernatant was measured using spectrometre- $\gamma$. The analysis showed that the optimum weight of $\mathrm{CsNO}_{3}$ addition when most binding of ${ }^{137} \mathrm{Cs}$ occurred was $700 \mathrm{mg}$ equal to $0.0472 \mathrm{~g}{ }^{137} \mathrm{Cs}$ isotope, while the optimum weight addition of Lampung zeolite was $1000 \mathrm{mg}$ until $1200 \mathrm{mg}$ equal to ${ }^{137} \mathrm{Cs}$ isotope content in ${ }^{137} \mathrm{Cs}$-zeolite obtained was $0.0557 \mathrm{~g}$. The ${ }^{137} \mathrm{Cs}$ isotope separation process using both methods could be concluded that the cation exchange method using zeolite by the addition of 1000 mg Lampung zeolite until $1200 \mathrm{mg}$ had better result than the precipitation method. The other advantages of this method were easier and saver than precipitation methods that the process should be in ice batch $\left(-4^{\circ} \mathrm{C}\right)$, using chemicals $\mathrm{HClO}_{4}$, acetone and ethanol which had volatile and exothermic character.

Keywords: $\quad{ }^{137} \mathrm{Cs}$ isotope, zeolite, $\mathrm{CsNO}_{3}$ powder, cation exchange and precipitation method. 


\section{PENDAHULUAN}

PEB $\mathrm{U}_{3} \mathrm{Si}_{2}-\mathrm{Al}$ pasca iradiasi mengandung beberapa hasil fisi antara lain isotop ${ }^{137} \mathrm{Cs}$, ${ }^{144} \mathrm{Ba}$, dan ${ }^{90} \mathrm{Sr}$ dan beberapa unsur bermassa berat (heavy element, $\mathrm{HE}$ ) seperti isotop $\mathrm{U}$ dan $\mathrm{Pu}$. Isotop ${ }^{144} \mathrm{Ba}$ adalah isotop hasil fisi yang masih dapat meluruh dan menghasilkan isotop-isotop lain sebagai hasil fisi yang lebih stabil diantaranya isotop ${ }^{90} \mathrm{Sr}$ dan ${ }^{137} \mathrm{Cs}{ }^{[1]}$. Isotop ${ }^{137} \mathrm{Cs}$ mempunyai waktu paroh ( $\mathrm{t}_{1 / 2}: 30,17$ tahun) dan fission yield (Fy:6,2\%), sehingga isotop ${ }^{137} \mathrm{Cs}$ mempunyai keunggulan untuk dapat dijadikan salah satu isotop monitor burn up.

Untuk mengetahui kandungan isotop hasil fisi dan $\mathrm{HE}$ dalam pelat elemen bakar (PEB) $\mathrm{U}_{3} \mathrm{Si}_{2}-\mathrm{Al}$ pasca iradiasi diperlukan metode valid agar diperoleh data yang akurat. Umumnya isotop hasil fisi dan HE adalah isotop pemancar radiasi $\alpha, \beta, \gamma$, dan untuk menentukan komposisi kimianya dapat dilakukan dengan menggunakan metode spektrometri[2,3].Pengukuran dengan menggunakan metode spektrometri, harus dilakukan dengan proses pemisahan antara isotop pemancar gamma dengan isotop pemancar alpha terlebih dahulu. Untuk selanjutnya dapat dianalisis menggunakan spektrometer- $\alpha$ maupun spektrometer- $\gamma$. Pemisahan isotop hasil fisi dengan HE semestinya tidak perlu dilakukan, bila PTBBN mempunyai alat spektrometer massa, tetapi karena PTBBN belum mempunyai alat tersebut maka untuk melakukan analisis fisikokimia bahan bakar pasca iradiasi harus dilakukan pemisahan. Pemisahan hasil fisi khususnya ${ }^{137} \mathrm{Cs}$ bertujuan untuk mendapatkan komposisi kimia isotop secara kuantitatif. Pemisahan dapat dilakukan dengan menggunakan metode pengendapan maupun penukar kation. Beberapa hal yang menyebabkan hasil pengukuran kurang akurat dengan spektrometri antara lain adalah konsentrasi isotop $U$ dalam bahan bakar lebih besar dari pada isotop Cs. Daya tembus isotop Cs lebih besar dibandingkan dengan isotop $U$ dan $\mathrm{Pu}$, walaupun energi antara isotop Cs dengan isotop $\mathrm{U}$ dan $\mathrm{Pu}$ jauh berbeda. Sebagai akibatnya pada saat pengukuran dengan spektrometer- $\alpha$, spektrum isotop $U$ dan $\mathrm{Pu}$ akan tertutup oleh spektrum isotop Cs sebagai pemancar sinar- $\gamma$. Oleh karena itu, sebelum melakukan pengukuran dengan spektrometri perlu dilakukan pemisahan isotop hasil fisi ${ }^{137} \mathrm{Cs}$ dari isotop $U$ sebagai HE.

Beberapa metode yang dapat digunakan untuk memisahkan isotop ${ }^{137} \mathrm{Cs}$ dengan isotop lainnya dalam $\mathrm{PEB} \mathrm{U}_{3} \mathrm{Si}_{2}-\mathrm{Al}$ pasca iradiasi antara lain adalah metode ekstraksi, metode pengendapan langsung sebagai $\mathrm{CsClO}_{4}$ dan metode penukar kation dengan penambahan zeolit Lampung. Pada penelitian sebelumnnya telah dilakukan pemisahan standar ${ }^{137} \mathrm{Cs}$ dari SRM $4233 \mathrm{E}$ dengan ketiga metode diatas dan telah diperoleh besar recovery pemisahan masing-masing metode. Hasil analisis recovery pemisahan standar ${ }^{137} \mathrm{Cs}$ dengan metode ekstraksi belum menunjukkan hasil yang baik karena diperoleh besar recovery pemisahan ${ }^{137} \mathrm{Cs}$ sangat kecil yaitu sebesar $28,03 \% \pm 5,33 \%[4,5]$, sedangkan dengan metode pengendapan diperoleh recovery pemisahan isotop ${ }^{137} \mathrm{Cs}$ sebesar $98,01 \% \pm$ $1,11 \%\left[{ }^{[6]}\right.$ dan dengan metode penukar kation menggunakan zeolit diperoleh recovery pemisahan isotop ${ }^{137} \mathrm{Cs}$ sebesar $99,03 \% \pm$ $0,1 \%[6]$. Berdasarkan hasil penelitian tersebut, maka pada penelitian ini digunakan metode pengendapan dan metode penukar kation menggunakan zeolit Lampung untuk memisahkan isotop ${ }^{137} \mathrm{Cs}$ dari isotop lainnya yang terkandung dalam $\mathrm{PEB} \mathrm{U}_{3} \mathrm{Si}_{2}$-Al pasca iradiasi.

\section{a. Metode pengendapan $\mathrm{CsClO}_{4}$}

Pemilihan metode pengendapan dari ASTM E 320-90[7] digunakan untuk memisahkan isotop ${ }^{137} \mathrm{Cs}$ berdasarkan kepada hasil penelitian sebelumnya.Telah diketahui bahwa $\mathrm{HClO}_{4}$ selektif terhadap isotop ${ }^{137} \mathrm{Cs}$ bila dibandingkan dengan isotop ${ }^{90} \mathrm{Sr}$ maupun uranium ${ }^{[8,9]}$. Dalam 
melakukan pemisahan isotop ${ }^{137} \mathrm{Cs}$ dalam larutan $\mathrm{PEB} \mathrm{U}_{3} \mathrm{Si}_{2}-\mathrm{Al}$ pasca iradiasi harus ditambahkan serbuk $\mathrm{CsNO}_{3}$ sebagai carrier atau senyawa pembawa di dalam media $\mathrm{HClO}_{4}$. Penambahan serbuk $\mathrm{CsNO}_{3}$ untuk memudahkan proses pengendapan, karena kandungan isotop ${ }^{137} \mathrm{Cs}$ dalam larutan sampel bahan bakar nuklir pasca iradiasi yang dianalisis sangat kecil (1 tetes) dan mengalami pengenceran hingga $10 \mathrm{~mL}$ membuat proses pengendapannya cukup sulit dihasilkan. Jumlah sampel larutan PEB $\mathrm{U}_{3} \mathrm{Si}_{2}-\mathrm{Al}$ yang dianalisis hanya $150 \mu \mathrm{L}$ dari $10 \mathrm{~mL}$ dan hal ini dilakukan untuk menghindari paparan radiasi terhadap pekerja radiasi di laboratorium. Oleh karena itu, dalam proses pengendapan isotop ${ }^{137} \mathrm{Cs}$ dibutuhkan suatu senyawa pembawa untuk meningkatkan kandungan ion cesium. Persyaratan senyawa pembawa yang ditambahkan harus mempunyai sifat kimia yang sama dari ion yang akan diendapkan dan merupakan garam dari isotop ion logam yang akan dipisahkan. Berdasarkan hal tersebut maka pada proses pengendapan ${ }^{137} \mathrm{Cs}$ dari larutan bahan bakar nuklir dibutuhkan penambahan garam $\mathrm{Cs}$ dari $\mathrm{CsNO}_{3}$ dalam media $\mathrm{HClO}_{4}$. Senyawa pembawa akan meningkatkan konsentrasi ion $\mathrm{Cs}^{+}$dalam larutan, sehingga pada saat ion tersebut diendapkan sebagai garam $\mathrm{CsClO}_{4}$, akan mengadsorpsi ${ }^{137} \mathrm{Cs}$ aktif secara maksimum dan menyebabkan pembentukan endapan ${ }^{137} \mathrm{CsClO}_{4}$ juga secara maksimun, sedangkan penggunaan media perchlorat disebabkan karena endapan ${ }^{137} \mathrm{CsClO}_{4}$ memiliki kelarutan rendah pada temperatur $0^{\circ} \mathrm{C}^{[10]}$.Oleh karena itu proses pengendapan isotop ${ }^{137} \mathrm{Cs}$ dengan penambahan larutan $\mathrm{HClO}_{4}$ harus dilakukan di dalam pengangas es (ice bath) pada temperatur di bawah $0^{\circ} \mathrm{C}\left(-4^{\circ} \mathrm{C}\right)$ agar terbentuk endapan ${ }^{137} \mathrm{CsClO}_{4}$ secara sempurna. Fenomena terjadinya reaksi pengendapan ${ }^{137} \mathrm{CsClO}_{4}$ mengikuti reaksi berikut ${ }^{[9]}$ :

$\mathrm{CsNO}_{3}+\mathrm{H}_{2} \mathrm{O} \rightarrow \mathrm{Cs}^{+}+\mathrm{NO}_{3}$

$\mathrm{Cs}^{+}+{ }^{137} \mathrm{Cs}^{+}+\mathrm{HClO}_{4} \rightarrow{ }^{137} \mathrm{CsClO}_{4}$ (endapan) $+\mathrm{H}^{+}$
Dari reaksi diatas, isotop ${ }^{137} \mathrm{Cs}$ akan terikat di dalam endapan ${ }^{137} \mathrm{CsClO}_{4}$ sebagai fasa padat dan isotop uranium berada di dalam supernatan sebagai fasa cair. Isotop ${ }^{137} \mathrm{Cs}$ yang telah terikat dalam bentuk endapan ${ }^{137} \mathrm{CsClO}_{4}$, kemudian dicuci menggunakan etanol dan aceton. Pencucian dilakukan untuk menghilangkan ion-ion yang terlarut dalam endapan seperti $\mathrm{Cl}^{-}$dan $\mathrm{NO}_{3}{ }^{-}$dan selanjutnya dikeringkan dalam oven untuk menghilangkan kandungan airnya. Pemilihan aceton sebagai larutan pencuci disebabkan karena endapan ${ }^{137} \mathrm{CsClO}_{4}$ bersifat polar dan mudah larut di dalam air dan untuk meminimalkan kelarutan endapan ${ }^{137} \mathrm{CsClO}_{4}$ dalam proses pencucian tersebut digunakan pelarut non polar (aceton). Endapan ${ }^{137} \mathrm{CsClO}_{4}$ yang telah kering kemudian ditimbang dan diukur besar kandungan isotop ${ }^{137} \mathrm{Cs}$ dan keradioaktifannya menggunakan spektrometer- $\gamma^{[11]}$.

\section{b. Metode penukar kation menggunakan Zeolit Lampung}

Zeolit digunakan sebagai bahan penukar kation karena merupakan kristal aluminosilikat terhidrasi yang mengandung kation alkali atau alkali tanah dalam kerangka tiga dimensi dan banyak diperoleh di Indonesia. Kerangka dasar struktur zeolit terdiri dari unit tetrahedral $\mathrm{AlO}_{2}$ dan $\mathrm{SiO}_{2}$ yang saling berhubungan melalui atom $\mathrm{O}$. Atom $\mathrm{Si}^{4+}$ akan digantikan oleh $\mathrm{Al}^{3+}$, sehingga terjadi defisiensi muatan positif seperti yang ditunjukkan pada Gambar 1.

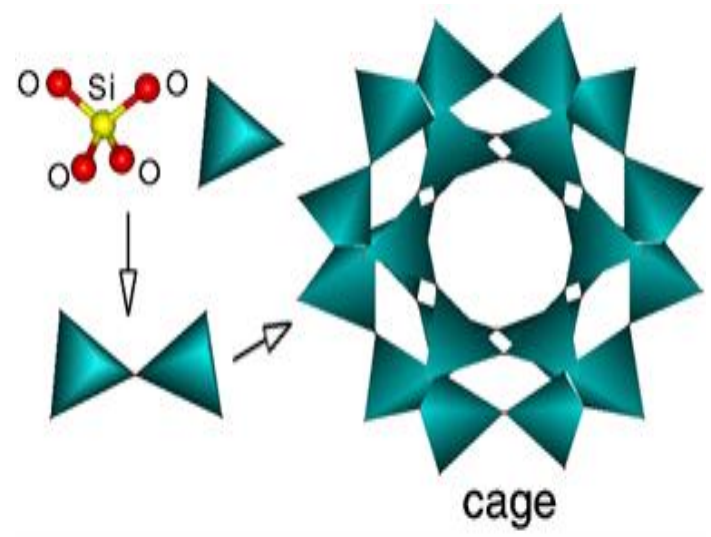

Gambar 1. Kerangka struktur zeolit [9] 
Defesiensi muatan ini menyebabkan zeolit bermuatan negatif dan selanjutnya akan dinetralkan oleh kation alkali atau alkali tanah, seperti $\mathrm{Na}^{+}, \mathrm{K}^{+}, \mathrm{Mg}^{2+}$ dan $\mathrm{Ca}^{2+} \mathrm{di}$ dalam rongganya sehingga mencapai senyawa yang stabil. Selain itu, agar proses tukar kation dapat berjalan baik, sebelum zeolit Lampung digunakan sebagai bahan penukar kation untuk isotop cesium terlebih dahulu zeolit diaktifasi dengan $\mathrm{NH}_{4} \mathrm{Cl}$ agar terbentuk monokationik zeolit $\left(\mathrm{NH}_{4} \mathrm{Z}\right)$. Diharapkan semua kation yang berada dalam zeolit Lampung setelah mengalami proses aktifasi dengan $\mathrm{NH}_{4} \mathrm{Cl}$ dapat digantikan dengan kation amonium secara homogen atau monokationik. $\mathrm{NH} 4$-zeolite $\left(\mathrm{NH}_{4}-\mathrm{Z}\right)$ yang terbentuk kemudian digunakan untuk bahan penukar kation isotop cesium. Proses aktifasi yang terjadi antara zeolit Lampung dengan $\mathrm{NH} 4 \mathrm{Cl}$ jenuh mengikuti persamaan reaksi kimia sbb[12]:

Zeolit $\left(\mathrm{M}^{\mathrm{n}+}\right)+\mathrm{NH}_{4} \mathrm{Cl} \rightarrow \mathrm{NH}_{4}$-Zeolit $+\mathrm{M}^{\mathrm{n}+} \mathrm{Cl}$ dengan :

$$
\begin{aligned}
M= & \text { logam alkali dan alkali tanah } \\
& \text { (kation dari zeolit alam) } \\
n= & \text { elektron valensi logam }
\end{aligned}
$$

Selanjutnya isotop ${ }^{137} \mathrm{Cs}$ dalam bahan bakar nuklir akan terikat dengan zeolit dalam bentuk padatan ${ }^{137} \mathrm{Cs}$-zeolit dengan reaksi kimia seperti berikut:

$\mathrm{NH}_{4}$-Zeolit $+{ }^{137} \mathrm{Cs} \rightarrow{ }^{137} \mathrm{Cs}$-Zeolit $+\mathrm{NH}_{4}{ }^{+}$

Senyawa $\mathrm{NH}_{4}$-zeolit mempunyai jarijari ion sebesar $331 \mathrm{pm}$, sedangkan $\mathrm{Cs}^{+}$ mempunyai jari-jari ion sebesar $329 \mathrm{pm}$. Hal ini menyebabkan $\mathrm{Cs}^{+}$lebih mudah bertukar dengan $\mathrm{NH}_{4}{ }^{+}$dalam kerangka zeolit dibandingkan dengan dengan isotop $\mathrm{U}^{6+}$ maupun $\mathrm{Pu}^{6+}$ yang mempunyai jari-jari ion masing-masing sebesar $97 \mathrm{pm}$ dan $81 \mathrm{pm}$. Proses pemisahan dengan metode penukar kation isotop ${ }^{137} \mathrm{Cs}$ terikat di dalam zeolit sebagai fasa padat, sedangkan isotop lainnya tidak terikat di dalam zeolit, tetapi lolos sebagai supernatan di dalam fasa cair. Fenomena inilah yang terjadi di dalam proses penukar kation untuk memungut isotop ${ }^{137} \mathrm{Cs}$ dari $\mathrm{U}$ dan $\mathrm{Pu}$ dalam bahan bakar pasca iradiasi.

Kandungan isotop ${ }^{137} \mathrm{Cs}$ dalam endapan ${ }^{137} \mathrm{CsClO} 4$ dan padatan ${ }^{137} \mathrm{Cs}$-zeolit selanjutnya diukur dengan menggunakan spektrometer- $\gamma$. Hasil pengukuran isotop ${ }^{137} \mathrm{Cs}$ dengan spektrometer- $\gamma$ diperoleh berupa cacahan per detik (cps), kemudian di evaluasi dengan menggunakan rumus persamaan (1) dan (2) sehingga diperoleh komposisi isotop ${ }^{137} \mathrm{Cs}$ secara kuantitatif dengan berat tertentu di dalam sampel bahan bakar nuklir. Kandungan isotop tersebut dapat dihitung dengan rumus sebagai berikut ${ }^{[11]}$ :

$$
\begin{aligned}
& E f f=\frac{C i}{A k t \cdot I i} \\
& N=\frac{A k t}{E f f \cdot \text { Irel. } \lambda}
\end{aligned}
$$

\begin{tabular}{|c|c|}
\hline $\mathrm{Si}$ & jumlah cacahan, \\
\hline & $\begin{array}{l}\text { : faktor yield intensitas dari isotop- } \\
\text { (lihat daftar tabel isotop) }\end{array}$ \\
\hline N & $\begin{array}{l}\text { : jumlah isotop dalam berat tertentu } \\
\text { sampel bahan bakar nuklir }\end{array}$ \\
\hline Akt & keaktifan isotop, $\mathrm{Bq}$ \\
\hline Eff & efisiensi detektor \\
\hline Irel & $\begin{array}{l}\text { Intensitas relatif puncak isotop } \\
\text { tertentu pada energi yang diukur }\end{array}$ \\
\hline & $\begin{array}{l}\text { konstanta peluruhan atau (In } \\
2) / T_{1 / 2}\end{array}$ \\
\hline $\mathrm{T}_{1 / 2}$ & $\begin{array}{l}\text { waktu paruh dari isotop }{ }^{137} \mathrm{Cs}= \\
30,17 \text { tahun }\end{array}$ \\
\hline
\end{tabular}

\section{Dimana:}

\section{METODOLOGI}

Pengukuran aktivitas isotop ${ }^{137} \mathrm{Cs}$ dilakukan terhadap 2 buah (duplo) larutan standar ${ }^{137} \mathrm{Cs}$ SRM $4233 \mathrm{E}$ sebanyak $50 \mu \mathrm{L}$ dalam $2 \mathrm{ml} \mathrm{HCl} 0,1 \mathrm{~N}$, yang digunakan untuk mengetahui validasi metode dengan cara menentukan efisiensi detektor, SD, akurasi, presisi pengukuran dan recovery pemisahan. Setelah diketahui validasi metode, selanjutnya dilakukan pemisahan 
${ }^{137} \mathrm{Cs}$ dalam larutan $\mathrm{PEB} \mathrm{U}_{3} \mathrm{Si}_{2}-\mathrm{Al}$ pasca iradiasi menggunakan metode pengendapan maupun metode penukar kation. Larutan PEB $\mathrm{U}_{3} \mathrm{Si}_{2}$-Al pasca iradiasi potongan bagian tengah dengan kode TMU-M1 dipipet 1 tetes, kemudian diencerkan menjadi $10 \mathrm{~mL}$ untuk mengurangi paparan radiasi bagi pekerja di laboratorium. Analisis kandungan ${ }^{137} \mathrm{Cs}$ menggunakan larutan $\mathrm{PEB}$ $\mathrm{U}_{3} \mathrm{Si}_{2}$-Al sebanyak $150 \mu \mathrm{L}$ dari $10 \mathrm{~mL}$ dan masing-masing di masukkan ke dalam 3 (tiga) buah vial (triplo). Ke dalam masingmasing vial ditambahkan serbuk $\mathrm{CsNO}_{3}$ dengan variasi berat $500 ; 625 ; 700$; dan 1000 mg. Penggunaan variasi berat $\mathrm{CsNO}_{3}$ pada penelitian ini mengacu kepada hasil penelitian sebelumnya dengan penambahan berat serbuk $\mathrm{CsNO}_{3} 225 \mathrm{mg}^{[11]}$. Pada penelitian lanjutan ini digunakan serbuk $\mathrm{CsNO}_{3}$ lebih besar dari $225 \mathrm{mg}$ yaitu 500; 625; 700 ; dan 1000 mg. Proses pengendapan dilakukan sama dengan perlakuan terhadap sampel standar dengan penambahan $\mathrm{HClO}_{4}$ sebanyak $4 \mathrm{~mL}$ di dalam pengangas es pada temperatur $-4^{\circ} \mathrm{C}$ dan didiamkan selama 1 jam. Proses pengendapan menghasilkan pemisahan antara endapan ${ }^{137} \mathrm{CsClO}_{4}$ sebagai fasa padat dengan isotop lainnya dalam fasa cair atau supernatan. Endapan $\mathrm{CsClO}_{4}$ yang terbentuk kemudian dibilas dengan etanol yang diikuti oleh aceton. Endapan $\mathrm{CsClO}_{4}$ yang sudah kering, kemudian diukur dengan menggunakan spektrometer- $\gamma$. Pengukuran dilakukan dengan waktu cacah 300 detik dan jarak detektor dengan sampel $16 \mathrm{~cm}$ dan dilakukan pengukuran dengan 3 (tiga) kali pengulangan. Hasil pemisahan isotop ${ }^{137} \mathrm{Cs}$ dengan metode pengendapan akan dibandingkan dengan metode penukar kation sehingga diketahui besar pemisahan isotop ${ }^{137} \mathrm{Cs}$ dalam $\mathrm{PEB} \quad \mathrm{U}_{3} \mathrm{Si}_{2}-\mathrm{Al}$ pasca iradiasi.

Pemisahan ${ }^{137} \mathrm{Cs}$ dalam larutan PEB $\mathrm{U}_{3} \mathrm{Si}_{2}$-Al pasca iradiasi dengan metode penukar kation dengan penambahan zeolit Lampung dengan variasi berat 700; 900 ; 1000 dan $1200 \mathrm{mg}$. Larutan PEB U $\mathrm{U}_{3} \mathrm{Si}_{2}$-Al pasca iradiasi dipipet sebanyak $150 \mu \mathrm{L}$ dan masing-masing di masukkan ke dalam 3 (tiga) buah vial dan ditambahkan zeolit Lampung dengan variasi berat diatas, selanjutnya dilakukan proses penukar kation dengan pengadukan selama 1 jam menggunakan shaker dengan kecepatan 1000 rpm, setelah selesai didiamkan selama 24 jam, sehinnga menghasilkan pemisahan antara padatan ${ }^{137}$ Cs-zeolit sebagai fasa padat dengan isotop $\mathrm{U}, \mathrm{Pu}$ dalam fasa cair. Padatan ${ }^{137} \mathrm{Cs}$-zeolit hasil proses penukar kation dipisahkan dari larutan supernatan dengan cara memipet secara berlahanlahan. Paduan ${ }^{137} \mathrm{Cs}$-zeolit dikeringkan dan ditimbang, selanjutnya untuk mengetahui kandungan isotop ${ }^{137} \mathrm{Cs}$ di dalam padatan ${ }^{137} \mathrm{Cs}$-zeolit dilakukan pengukuran menggunakan spektrometer- $\gamma$ pada energi 661 kev dengan waktu cacah 300 detik pada jarak $16 \mathrm{~cm}$ dari detektor.

\section{HASIL DAN PEMBAHASAN}

Hasil pengukuran aktivitas ${ }^{137} \mathrm{Cs}$ terhadap 2 sampel larutan standar isotop ${ }^{137} \mathrm{Cs}$ SRM 4233E diperoleh berupa cacahan per detik (cps). Cacahan tersebut dievaluasi dengan menggunakan persamaan (1) dan (2) dan diperoleh besaran efisiensi detektor seperti yang tercantum pada Tabel 1 dan cacahan tersebut digunakan juga untuk menghitung besar SD, presisi dan akurasi seperti yang dicantumkan pada Tabel 2 . 
Tabel 1. Data perhitungan efisiensi detektor spektrometer- $\gamma$

\begin{tabular}{|c|c|c|c|c|}
\hline $\begin{array}{c}\text { Aktivitas standar } \\
50 \mu \mathrm{L}^{137} \mathrm{Cs}, \mathrm{Bq}\end{array}$ & $\begin{array}{c}\text { Net } \\
\text { Area }\end{array}$ & $\begin{array}{c}\text { Cacah per } \\
\text { detik }\end{array}$ & $\begin{array}{c}l \gamma \\
\text { (tabel) }\end{array}$ & $\begin{array}{l}\text { Efisiensi } \\
\text { Detektor }\end{array}$ \\
\hline $\begin{array}{l}\text { Tahun } \\
2015\end{array}$ & (cacah) & & & \\
\hline \multirow{4}{*}{9582,96} & 23585 & \multirow{4}{*}{15,6747} & \multirow{4}{*}{85,1} & \multirow{4}{*}{0,1914} \\
\hline & 23355 & & & \\
\hline & 23596 & & & \\
\hline & 23512 & & & \\
\hline
\end{tabular}

Tabel 1 menunjukkan bahwa efisiensi detektor pada jarak $16 \mathrm{~cm}$ diperoleh sebesar 0,1914\% dengan SD, akurasi dan presisi pengukuran diperoleh masing- masing sebesar 617,$10 ; 0,376 \%$ dan $1,875 \%$ seperti yang ditunjukkan pada Tabel 2.

Tabel 2. Akurasi dan Presisi Pengukuran Standar ${ }^{137} \mathrm{Cs}$

\begin{tabular}{|c|c|c|c|c|}
\hline No & $\begin{array}{l}\text { Net Area } \\
\text { (cacah) }\end{array}$ & $\begin{array}{l}\text { Cacah/detik } \\
\text { (cps) }\end{array}$ & $\begin{array}{c}\text { Aktivitas } \\
\text { Pengukuran } \\
(\mathrm{Bg})\end{array}$ & $\begin{array}{l}\text { Aktivitas } \\
\text { Sertifikat } \\
(\mathrm{Bq})\end{array}$ \\
\hline 1. & 21853 & 14,361 & 31841,12 & \multirow[t]{11}{*}{32802,578} \\
\hline 2. & 22308 & 14,872 & 32934,39 & \\
\hline 3. & 22714 & 15,142 & 33573,52 & \\
\hline 4. & 22310 & 14,870 & 32976,37 & \\
\hline 5. & 21910 & 14,606 & 32385,13 & \\
\hline 6. & 22500 & 15,066 & 33405,02 & \\
\hline 7. & 22550 & 15,033 & 33331,12 & \\
\hline Rerata & & & 32926,78 & \\
\hline SD & & & 617,10 & \\
\hline Akurasi(\%) & & & 0.376 & \\
\hline Presisi (\%) & & & 1,875 & \\
\hline
\end{tabular}

Tabel 2 menunjukkan bahwa perbedaan besar aktivitas isotop ${ }^{137} \mathrm{Cs}$ hasil pengukuran dan aktivitas yang tercantum dalam sertifikat atau akurasi diperoleh sebesar $0,376 \%$. Untuk mengetahui keberterimaan nilai perbedaan tersebut, dilakukan uji t dengan mengambil derajat kepercayaan $95 \%$. Hasil perhitungan menunjukkan nilai uji t sebesar 0,0095 lebih kecil dari pada nilai $t$-tabel (Critical values of student's $t$ distribution, to.05 $=4,3)^{[13]}$. Hal ini menunjukkan bahwa tidak ada perbedaan yang signifikan antara aktivitas hasil pengukuran dengan sertifikat. Sementara itu, diperoleh besaran presisi pengukuran sebesar 1,875 $\%$ lebih kecil dari 5\% sehingga masih memenuhi kriteria keberterimaan kaidah statistik pada derajat kepercayaan 95\%. Berdasarkan data perhitungan diatas menunjukkan bahwa unjuk kerja peralatan spektrometer- $\gamma$ yang digunakan untuk pengukuran isotop ${ }^{137} \mathrm{Cs}$ telah memenuhi keberterimaan secara statistik.

Dalam melakukan validasi metode selain efisiensi detektor, SD, akurasi dan presisi ada hal penting yang harus diketahui yaitu recovery pemisahan isotop ${ }^{137} \mathrm{Cs}$ menggunakan metode pengendapan dan metode penukar kation. Penentuan recovery dari hasil cacahan padatan ${ }^{137} \mathrm{Cs}$-zeolit dan endapan ${ }^{137} \mathrm{CsClO}_{4}$ dari standar isotop ${ }^{137} \mathrm{Cs}$ SRM 4233E ditunjukkan pada Tabel 3. 
Tabel 3. Hasil analisis penentuan recovery analisis standar SRM isotop ${ }^{137} \mathrm{Cs}^{[5,14]}$

\begin{tabular}{|l|c|c|c|}
\hline \multicolumn{1}{|c|}{ Sampel } & $\begin{array}{c}\text { Kandungan }{ }^{137} \mathrm{Cs} \\
\text { sertifikat }(\mu \mathrm{g})\end{array}$ & $\begin{array}{c}\text { Kandungan }{ }^{137} \mathrm{Cs} \\
\text { pengukuran }(\mu \mathrm{g})\end{array}$ & $\begin{array}{c}\text { Recovery, } \\
\%\end{array}$ \\
\hline Larutan ${ }^{137} \mathrm{Cs} \mathrm{SRM-NIST}$ & 0,0037847 & 0,00376 & 99,23 \\
\hline Padatan ${ }^{137} \mathrm{Cs}-$-zeolit & 0,0037847 & 0,00375 & 99,03 \\
\hline Endapan ${ }^{137} \mathrm{CsClO} 4$ & 0,0037847 & 0,00373 & 98,01 \\
\hline
\end{tabular}

Tabel 3 menunjukkan bahwa hasil penentuan recovery sampel larutan $50 \mu \mathrm{L}$ SRM 4233E dalam $2 \mathrm{~mL} \mathrm{HCl} \mathrm{0,1M} \mathrm{diperoleh}$ sebesar 99,23 \%. Hasil ini dibandingkan dengan recovery padatan ${ }^{137} \mathrm{Cs}$-zeolit yang diperoleh sebesar 99,03 \% dan recovery endapan ${ }^{137} \mathrm{CsClO} 4$ yang diperoleh sebesar $98,01 \%$. Hal ini menunjukkan bahwa metode penukar kation dan metode pengendapan mampu menyerap isotop ${ }^{137} \mathrm{Cs}$ dalam $50 \mu \mathrm{L}$ SRM 4233E hingga $98 \%$. Besaran recovery ini digunakan sebagai faktor koreksi untuk penentuan kandungan isotop ${ }^{137} \mathrm{Cs}$ dalam larutan PEB
$\mathrm{U}_{3} \mathrm{Si}_{2}$-Al pasca iradiasi dengan metode dan parameter pengukuran yang sama.

Parameter berat $\mathrm{CsNO}_{3}$ pada metode pengendapan yang digunakan untuk pemisahan isotop ${ }^{137} \mathrm{Cs}$ dalam larutan PEB $\mathrm{U}_{3} \mathrm{Si}_{2}-\mathrm{Al}$ pasca iradiasi mengacu kepada hasil penelitian sebelumnya ${ }^{[10,12]}$. Hasil pengukuran isotop ${ }^{137} \mathrm{Cs}$ dalam larutan PEB $\mathrm{U}_{3} \mathrm{Si}_{2}-\mathrm{Al}$ pasca iradiasi menggunakan metode pengendapan dengan penambahan $\mathrm{CsNO}_{3}$ seberat $225 \mathrm{mg}$ diperoleh cacah isotop ${ }^{137} \mathrm{Cs}$ dalam supernatan masih cukup besar seperti yang ditunjukkan pada Tabel 4.

Tabel 4. Kandungan isotop ${ }^{137} \mathrm{Cs}$ dalam endapan $\mathrm{CsClO}_{4}$ dan supernatan ${ }^{[10,12]}$

\begin{tabular}{|c|c|c|c|c|c|}
\hline Sampel & $\begin{array}{c}\text { Net Area } \\
(\text { Cacah) }\end{array}$ & $\begin{array}{c}\text { Cacah per detik } \\
(\mathrm{cps})\end{array}$ & $\begin{array}{c}\mathrm{l} \gamma \\
\text { tabel } \\
(\%)\end{array}$ & $\begin{array}{c}\text { Kand. }{ }^{137} \mathrm{Cs} \\
\text { dalam endapan } \\
(\mu \mathrm{g})\end{array}$ & $\begin{array}{c}\text { Kand. }{ }^{137} \text { Cs dalam } \\
\text { supernatan } \\
(\mu \mathrm{g})\end{array}$ \\
\hline $\begin{array}{c}\text { Endapan } \\
\mathrm{CsClO}_{4}\end{array}$ & $\begin{array}{c}79647 \\
79460\end{array}$ & 53,0627 & 85,1 & 0,01235 & - \\
\hline & $\begin{array}{c}79679 \\
12913\end{array}$ & 2,7436 & 85,1 & - & 0,00067 \\
Supernatan & 12810 & & & \\
\hline
\end{tabular}

Tabel 4 menunjukkan bahwa pemungutan isotop ${ }^{137} \mathrm{Cs}$ di dalam larutan PEB $\mathrm{U}_{3} \mathrm{Si}_{2}-\mathrm{Al}$ pasca iradiasi dengan penambahan $\mathrm{CsNO}_{3}$ seberat $225 \mathrm{mg}$, belum menunjukkan hasil yang baik, karena masih diperoleh jumlah cacah isotop ${ }^{137} \mathrm{Cs}$ dalam supernatan cukup besar yaitu rerata sebesar 12881 cacah atau sekitar $0,00067 \mu \mathrm{g}$. Hal ini menunjukkan bahwa $\mathrm{CsNO}_{3}$ dengan berat $225 \mathrm{mg}$ belum mampu mengendapkan secara sempurna kandungan isotop ${ }^{137} \mathrm{Cs}$ di dalam $150 \mu \mathrm{L}$ larutan PEB $U_{3} \mathrm{Si}_{2}-\mathrm{Al}$ pasca iradiasi. Dari percobaan ini belum diperoleh hasil pemungutan isotop ${ }^{137} \mathrm{Cs}$ dengan baik karena masih diperoleh kandungan isotop ${ }^{137} \mathrm{Cs}$ yang cukup besar di dalam supernatan, sehingga perlu dilakukan percobaan pemungutan isotop ${ }^{137} \mathrm{Cs}$ dalam larutan $\mathrm{PEB}$ $\mathrm{U}_{3} \mathrm{Si}_{2}$ - $\mathrm{Al}$ pasca iradiasi dengan penambahan serbuk $\mathrm{CsNO}_{3}$ lebih besar dari $225 \mathrm{mg}$ yaitu mulai dari berat $500 ; 625 ; 700$ dan 1000 mg.

Hasil pengukuran diperoleh cacah besarnya isotop ${ }^{137} \mathrm{Cs}$ di dalam endapan $\mathrm{CsClO}_{4}$ maupun di dalam supernatan pada masing-masing variasi penambahan berat $\mathrm{CsNO}_{3}$ dengan waktu cacah 300 detik ditunjukkan pada Tabel 5. 
Tabel 5. Kandungan isotop ${ }^{137} \mathrm{Cs}$ dalam endapan $\mathrm{CsClO}_{4}$ dan supernatan

\begin{tabular}{|c|c|c|c|c|}
\hline $\begin{array}{c}\text { Berat } \mathrm{CsNO}_{3} \\
(\mathrm{mg})\end{array}$ & $\begin{array}{c}\text { Net Area } \\
\text { endapan } \\
\mathrm{CsClO}_{4} \\
(\mathrm{cacah})\end{array}$ & $\begin{array}{c}\text { Kand. }{ }^{137} \mathrm{Cs} \\
\text { dalam endapan } \\
\mathrm{CsClO}_{4} \\
(\mu \mathrm{g})\end{array}$ & $\begin{array}{c}\text { Net Area } \\
\text { supernatan } \\
(\text { cacah })\end{array}$ & $\begin{array}{c}\text { Kand. }{ }^{137} \mathrm{Cs} \\
\text { dalam supernatan } \\
(\mu \mathrm{g})\end{array}$ \\
\hline 225 & 79594 & 0,0124 & 12881 & $0,00063^{[10,12]}$ \\
\hline 500 & 82572 & 0,0128 & 6538 & 0,00032 \\
\hline 625 & 84392 & 0,0458 & 1247 & 0,00006 \\
\hline 700 & 89788 & 0,0472 & 357 & 0,00002 \\
\hline 1000 & 87744 & 0,0472 & 352 & 0,00002 \\
\hline
\end{tabular}

Tabel 5 menunjukkan bahwa kandungan isotop ${ }^{137} \mathrm{Cs}$ dalam supernatan yang paling kecil terdapat pada penambahan serbuk $\mathrm{CsNO}_{3}$ sebanyak $700 \mathrm{mg}$ yaitu sebesar 0,00002 $\mu \mathrm{g}$ dan stabil hingga penambahan $\mathrm{CsNO}_{3}$ seberat $1000 \mathrm{mg}$. Hasil ini sesuai dengan yang dihara-pkan bahwa isotop ${ }^{137} \mathrm{Cs}$ di dalam sampel secara menyeluruh terikat oleh $\mathrm{CsNO}_{3}$ membentuk endapan $\mathrm{CsClO}_{4}$ dengan reaksi

$\mathrm{CsNO}_{3}+{ }^{137} \mathrm{Cs}+\mathrm{HClO}_{4} \rightarrow \mathrm{CsClO}_{4}$ (endapan) $+\mathrm{HNO}_{3}$

Dari reaksi diatas, isotop ${ }^{137} \mathrm{Cs}$ terikat di dalam endapan $\mathrm{CsClO}_{4}$ sebagai fasa padat dan tidak diharapkan berada dalam supernatan (fasa cair). Namun pada hasil analisis diatas, masih ada kandungan isotop ${ }^{137} \mathrm{Cs}$ di dalam supernatan walaupun dengan jumlah relatif kecil dan stabil. Hal ini terjadi karena pada saat pemipetan masih ada partikel endapan ${ }^{137} \mathrm{CsClO}_{4}$ yang terikut bersama supernatan. Parameter optimal yang diperoleh dalam metode pengendapan ini akan digunakan sebagai acuan untuk pemungutan isotop ${ }^{137} \mathrm{Cs}$ dalam bahan bakar PEB U $\mathrm{USi}_{2}$-Al pasca iradiasi.

Kandungan isotop ${ }^{137} \mathrm{Cs}$ dalam PEB $\mathrm{U}_{3} \mathrm{Si}_{2}$-Al pasca iradiasi yang diperoleh dari pemisahan dengan menggunakan metode pengendapan dibandingkan dengan kandungan isotop ${ }^{137} \mathrm{Cs}$ yang diperoleh dari pengukuran langsung (tanpa pemisahan). Hal ini dilakukan untuk mengetahui besar persentase pemungutan (recovery) isotop ${ }^{137} \mathrm{Cs}$ menggunakan metode pengendapan. Kandungan isotop ${ }^{137} \mathrm{Cs}$ yang diperoleh dari pengukuran langsung (tanpa pemisahan) menggunakan spektrometer- $\gamma$ ditunjukkan pada Tabel 6.

Tabel 6. Kandungan isotop ${ }^{137} \mathrm{Cs}$ di dalam $150 \mu \mathrm{L}$ PEB $\mathrm{U}_{3} \mathrm{Si}_{2}-\mathrm{Al}$ pasca iradiasi (tanpa pemisahan) $)^{[14]}$

\begin{tabular}{|c|c|c|c|c|c|c|}
\hline $\begin{array}{l}\text { Jenis } \\
\text { Isotop }\end{array}$ & $\begin{array}{c}\text { Net Area } \\
\text { (cacah) }\end{array}$ & $\begin{array}{l}\text { Cacah per } \\
\text { detik } \\
\text { (cps) }\end{array}$ & $\begin{array}{c}\text { l } \gamma \\
\text { tabel } \\
(\%)\end{array}$ & $\begin{array}{c}\text { Eff. } \\
\text { Detektor } \\
(\%) \\
\end{array}$ & $\begin{array}{c}\text { Aktivitas } \\
\text { jenis } \\
(\mathrm{Bq} / 150 \mu \mathrm{L}) \\
\end{array}$ & $\begin{array}{c}\text { Kand. }{ }^{137} \text { Cs dalam } \\
\text { larutan PEB } \\
(\mu \mathrm{g})\end{array}$ \\
\hline \multirow{4}{*}{${ }^{137} \mathrm{Cs}$} & 77669 & \multirow{4}{*}{51,773} & \multirow{4}{*}{85,1} & \multirow{4}{*}{0,1914} & \multirow{4}{*}{31710,257} & \multirow{4}{*}{0,0106} \\
\hline & 78001 & & & & & \\
\hline & 77309 & & & & & \\
\hline & 77660 & & & & & \\
\hline
\end{tabular}

Tabel 6 menunjukkan bahwa kandungan isotop ${ }^{137} \mathrm{Cs}$ yang terdapat di dalam $150 \mu \mathrm{L}$ PEB $U_{3} \mathrm{Si}_{2}-\mathrm{Al}$ pasca iradiasi dengan pengukuran langsung diperoleh kandungan isotop ${ }^{137} \mathrm{Cs}$ sebesar $0,0106 \mu \mathrm{g}$, sedangkan dengan metode pengendapan diperoleh sebesar 0,0472 $\mu \mathrm{g}$. Hal ini menunjukkan bahwa dengan pengukuran langsung menggunakan spektrometer- $\gamma$, kandungan isotop ${ }^{137} \mathrm{Cs}$ dalam $150 \mu \mathrm{L}$ PEB U $U_{3} \mathrm{Si}_{2}$-Al pasca iradiasi hanya terukur sebesar $78,67 \%$, sedangkan dengan metode 
pengendapan diperoleh recovery sebesar $98,01 \%$. Hal ini disebabkan karena pada sampel larutan $\mathrm{PEB} \mathrm{U}_{3} \mathrm{Si}_{2}-\mathrm{Al}$ pasca iradiasi yang diukur secara langsung masih ada hasil fisi selain cesium maupun heavy element (uranium dan plutonium) serta impuritas lainnya yang ikut berkompetisi dalam pengukuran [15], sehingga yang terukur dengan spektrometer- $\gamma$ hanya $78,67 \%$.

Pemisahan isotop ${ }^{137} \mathrm{Cs}$ dalam larutan $\mathrm{PEB} \mathrm{U}_{3} \mathrm{Si}_{2}$-Al pasca iradiasi menggunakan metode penukar kation dengan penambahan zeolit Lampung variasi berat 700; 900; 1000 dan 1200 mg ditunjukkan pada Tabel 7. Hasil pemisahan diperoleh padatan ${ }^{137} \mathrm{Cs}$-zeolit sebagai fasa padat dan isotop lainnya dalam supernatan. Tabel 7 menunjukkan bahwa penambahan zeolit dengan variasi berat 700; 900; 1000 hingga 1200 mg tidak memberikan perbedaan yang berarti terhadap besar penyerapan kandungan isotop ${ }^{137} \mathrm{Cs}$ dalam padatan ${ }^{137} \mathrm{Cs}$-zeolit. Hal ini disebabkan karena kapasitas tukar kation (KTK) zeolit Lampung sebesar 0,0049 meq/g (nilai KTK zeolit Lampung telah ditentukan pada penelitian sebelumnya) yang artinya secara perhitungan, setiap 1 gram zeolit Lampung dapat mengikat kation ${ }^{137} \mathrm{Cs}$ sebesar 0,0049 meq atau sebesar $670 \mu \mathrm{g}^{[16]}$.

Tabel 7. Kandungan isotop ${ }^{137} \mathrm{Cs}$ dalam padatan ${ }^{137} \mathrm{Cs}-z e o l i t$ dan supernatan

\begin{tabular}{|c|c|c|c|c|}
\hline $\begin{array}{c}\text { Berat } \\
\text { zeolit } \\
(\mathrm{mg})\end{array}$ & $\begin{array}{c}\text { Net Area } \\
\text { Padatan }{ }^{137} \mathrm{Cs}- \\
\text { zeolit } \\
(\text { cacah }\end{array}$ & $\begin{array}{c}\text { Kand. } .^{137} \mathrm{Cs} \\
\text { dalam padatan zeolit } \\
(\mu \mathrm{g})\end{array}$ & $\begin{array}{c}\text { Net Area } \\
\text { supernatan } \\
(\text { cacah })\end{array}$ & $\begin{array}{c}\text { Kand. }{ }^{137} \mathrm{Cs} \\
\text { dalam supernatan } \\
(\mu \mathrm{g})\end{array}$ \\
\hline 700 & 79303 & 0,0533 & 8381 & 0,00043 \\
\hline 900 & 82554 & 0,0555 & 4538 & 0,00016 \\
\hline 1000 & 82791 & 0,0557 & 312 & 0,00015 \\
\hline 1200 & 82792 & 0,0557 & 312 & 0,00015 \\
\hline
\end{tabular}

Tabel 7 menunjukkan bahwa kandungan isotop ${ }^{137} \mathrm{Cs}$ dalam padatan ${ }^{137}$ Cs-zeolit diperoleh paling besar pada penambahan zeolit Lampung $1000 \mathrm{mg}$ yaitu sebesar $0,0557 \mu \mathrm{g}$, demikian halnya dengan kandungan ${ }^{137} \mathrm{Cs}$ dalam supernatan yang paling kecil terdapat pada penambahan zeolit Lampung sebanyak $1000 \mathrm{mg}$ yaitu sebesar $0,00015 \mu \mathrm{g}$ dan stabil hingga penambahan zeolit lampung seberat 1200 mg.Hal ini menunjukkan bahwa KTK zeolit Lampung sebesar 0,0049 meq/g dengan berat zeolit $1000 \mathrm{mg}$ hingga $1200 \mathrm{mg}$ mampu mengikat isotop ${ }^{137} \mathrm{Cs}$ yang terdapat di dalam $150 \mu \mathrm{L}$ larutan pasca iradiasi secara sempurna.

\section{SIMPULAN}

Recovery pemisahan ${ }^{137} \mathrm{Cs}$ menggunakan standar larutan $50 \mu \mathrm{L}$ SRM 4233E dengan metode pengendapan dan metode penukar kation diperoleh masing-masing sebesar 98,01\% dan 99,03\%. Berat optimal serbuk $\mathrm{CsNO}_{3}$ yang digunakan sebagai carrier dalam metode pengendapan sebesar $700 \mathrm{mg}$, sedangkan berat optimal zeolit Lampung yang digunakan sebagai bahan penukar kation sebesar $1000 \mathrm{mg}$ hingga $1200 \mathrm{mg}$. Pemisahan isotop ${ }^{137} \mathrm{Cs}$ dalam $\mathrm{PEB} \mathrm{U}_{3} \mathrm{Si}_{2}-\mathrm{Al}$ pasca iradiasi menggunakan metode pengendapan diperoleh kandungan isotop ${ }^{137} \mathrm{Cs}$ dalam endapan ${ }^{137} \mathrm{CsClO}_{4}$ sebesar $0,0472 \mu \mathrm{g}$ dengan kandungan isotop ${ }^{137} \mathrm{Cs}$ sebesar $0,00002 \mu \mathrm{g}$ dalam supernatan. Pemisahan isotop ${ }^{137} \mathrm{Cs}$ dengan menggunakan metode penukar kation diperoleh kandungan isotop ${ }^{137} \mathrm{Cs}$ dalam padatan ${ }^{137} \mathrm{Cs}$-zeolit sebesar $0,0557 \mu \mathrm{g}$ dan $0,00015 \mu \mathrm{g}$ dalam supernatan. Pemisahan isotop ${ }^{137} \mathrm{Cs}$ menggunakan metode penukar kation dengan penambahan zeolit Lampung mempunyai keunggulan lebih baik karena hasil isotop ${ }^{137} \mathrm{Cs}$ yang diperoleh lebih besar dan pengerjaannya lebih mudah serta lebih aman bila dibandingkan dengan metode 
pengendapan yang pengerjaannya harus dalam penggangas es $\left(-4^{\circ} \mathrm{C}\right)$, penggunaan bahan kimia $\mathrm{HClO}_{4}$ dengan aceton dan etanol yang bersifat volatil dan eksotermik.

\section{UCAPAN TERIMA KASIH}

Ucapan terima kasih disampaikan kepada Ka.PTBBN dan Ka.Bid BUR yang telah meberikan dana DIPA tahun 2015 untuk membiayai peneltian ini, kepada lbu lis Haryati, Sutri Indaryati dan S.Nissa, dan rekan-rekan Kelompok Fisiko Kimia -Bidang Uji Radiometalurgi yang telah membantu pelaksanaan penelitian ini sehingga dapat ditulis dalam makalah.

\section{DAFTAR PUSTAKA}

[1] S. Amini, (1994), Sistim penukaran kation $\mathrm{Cs}$ dan $\mathrm{Sr}$ ke dalam zeolite untuk pengolahan limbah cair radioaktif, Prosiding Pertemuan dan Presentasi IImiah PPNY-BATAN, Yogyakarta, Buku-II, ISSN 0216-3128.

[2] Leenaers, E. Koonen, Y. Parthoens, P. Lemoine, S. Van den Berghe, (2008), Post-Irradiation Examination of AlFeNi cladded $\mathrm{U}_{3} \mathrm{Si}_{2}$ Fuel Plates Irradiated under Severe Conditions, Journal of Nuclear Material, Vol 375, Issue 2, page 243-253.

[3] A. Br. Ginting, D.Anggraini, Boybul, A.Nugroho, R.Kriswarini, (2014), Bunga Rampai, Proseding Hasil Penelitian Pusat Teknologi Bahan Bakar Nuklir, Pusat Teknologi Bahan Bakar NuklirBATAN, ISBN: 978-602-71975-0-3.

[4] A. H. Orabi, (2013), Determination of Uranium After Separation Using Solvent Extrction from Slightly Nitric Acid Solution and Spectrophotometric Detection, Journal of Radiation Research and Applied Sciences, Volume 6, Issue 2, October 2013, page 1-10.

[5] A.Br.Ginting, Boybul, A.Nugroho, D.Anggraini, R.Kriswarini, (2015), Pemisahan dan Analisis ${ }^{137} \mathrm{Cs}$ Dan ${ }^{235 \mathrm{U}}$
Dalam Pelat Elemen Bakar $\mathrm{U}_{3} \mathrm{Si}_{2}-\mathrm{Al}$ Pasca Iradiasi Untuk Penentuan Burn Up, Jurnal Teknologi Bahan Bakar Nuklir, Vol.11, Juni ,No.2,PTBBNBATAN, ISSN 1907-2635.

[6] Boybul, Yanlinastuti, S.Indaryati, A.Nugroho (2015), Penentuan Kandungan Isotop ${ }^{235} \mathrm{U}$ Dalam PEB $\mathrm{U}_{3} \mathrm{Si}_{2}-\mathrm{Al} \quad \mathrm{TMU} \quad 2,96 \mathrm{gU} / \mathrm{cm}^{3}$ Untuk Perhitungan Burn Up, URANIA, Jurnal Daur Bahan Bakar Nuklir, Vol.21, No.3, PTBBN-BATAN, ISSN 1907-2635.

[7] American Standard Test Methods ASTM-E 320-90,(1990), Standard Test Methods for Cesium-137 in Nuclear Fuel Solutions by Radiochemical Analysis, Standard Test Method For Nuclear Material, USA, Vol. 12.1.

[8] S.Amini, (2001), Studi Zeolit Untuk penukaran ion $\mathrm{Cs}$, Sr dan U, Proseding Hasil-Hasil Penelitian Elemen Bakar Nuklir P2TBDU-BATAN 1998/1999, ISSN 0854-5561, Serpong.

[9] H.T. Chae, H. Kim, C.S. Lee, B.J. Jun, J.M. Park, C.K. Kim, D.S. Sohn, (2008), Irradiation Tests for $\mathrm{U}_{3} \mathrm{Si}-\mathrm{Al}$ Dispersion Fuels with Aluminum Cladding, Journal of Nuclear Material, Vol 373, page 9-15, Korea Atomic Energy Research Institute P.O. Box 105, Yuseong, Daejeon 305-600, Republic of Korea.

[10] D.Anggraini, R. Kriswarini, (2009)," Penentuan Isotop Cs dari Unsur Cs Dalam Larutan Aktif $\mathrm{CsNO}_{3}$ ", URANIA, Jurnal Daur Bahan Bakar Nuklir, Vol.15, No.1, PTBN-BATAN, ISSN 1907-2635.

[11] L. P. Hong, S. Amini, A. G. Hutagaol, T.M. Sembiring, (2013), Nondestructive Burnup Verification By Gamma-Ray Spectroscopy Of LEU Silicide Fuel Plates Irradiated In The RSG GAS Multipurpose Reactor, Journal Annals of Nuclear Energy, Vol 56,June 2013,page 57- 65

[12] A. Br. Ginting, Boybul, A. Nugroho, D. Anggraini, R. Kriswarini, (2015), Analisis ${ }^{137} \mathrm{Cs}$ Dan ${ }^{235} \mathrm{U}$ Dalam Pelat Elemen Bakar $\mathrm{U}_{3} \mathrm{Si}_{2}-\mathrm{Al}$ Pasca Iradiasi 
Untuk Penentuan Burn Up, Jurnal Teknologi Bahan Bakar Nuklir, Vol.11, Juni ,No.2,PTBBN-BATAN, ISSN 19072635.

[13] A. Br. Ginting, (2012), Pemisahan dan Analisis Radionuklida ${ }^{137} \mathrm{Cs}$ di dalam PEB $U_{3} \mathrm{Si}_{2}-\mathrm{Al}$ Tingkat Muat Uranium $2,96 \mathrm{gU} / \mathrm{cm}^{3}$ Pasca Iradiasi, Jurnal Teknologi Bahan Nuklir-PTBN-BATAN, Vol.8 No.1, Januari.

[14] R. L, Anderson, (1987), Practical Statistics for Analytical Chemists" Van Nostrand Reinhold Company New York.

[15] A. Br. Ginting, Boybul, Yanlinastuti, A.Nugroho, D.Anggraini, R.Kriswarini,
(2015), Pengembangan Metode Baku Uji Fisikokimia PEB U $\mathrm{Si}_{2} / \mathrm{Al}$ TMU 4,8 $\mathrm{gU} / \mathrm{cm}^{3}$ Pasca Iradiasi, Proseding Hasil Penelitian Pusat Teknologi Bahan Bakar Nuklir-BATAN, ISBN: 978-60271975-0-3

[16] A. Nugroho, Boybul, A. Br. Ginting, (2014), Pemungutan Isotop Hasil Fisi ${ }^{137}$ Cs Dan Unsur Bermassa Berat Dari Bahan Bakar $\mathrm{U}_{3} \mathrm{Si}_{2}-\mathrm{Al}$ Pasca Iradiasi, Jurnal Teknologi Bahan Nuklir,Vol. 10, No.1, Juni 2014, Pusat Teknologi Bahan Bakar Nuklir - BATAN. 